\title{
Exogenous testosterone decreases men's sensitivity to vocal cues of male dominance
}

Chengyang Han

Christopher D. Watkins

Yu Nan

Jianxin Ou

Xue Lei

Xiangqian $\mathrm{Li}$

Yin Wu

This is the accepted manuscript (c) 2020, Elsevier Licensed under the Creative Commons

AttributionNonCommercial-NoDerivatives 4.0 International: http://creativecommons.org/licenses/by-nc-nd/4.0/

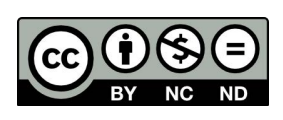

The published article is available from doi:

https://doi.org/10.1016/j.yhbeh.2020.104871 
Running title: Testosterone decreases dominance sensitivity

\title{
Exogenous testosterone decreases men's sensitivity to vocal cues of male dominance
}

\author{
Chengyang Han ${ }^{\mathrm{a}, \mathrm{b}}$, Christopher D. Watkins ${ }^{\mathrm{c}}$, Yu Nan ${ }^{\mathrm{a}, \mathrm{b}}$, Jianxin Ou ${ }^{\mathrm{a}, \mathrm{b}}, \mathrm{Xue} \mathrm{Lei}^{\mathrm{d}}$, \\ Xiangqian $\mathrm{Li}^{\mathrm{e}}$, Yin $\mathrm{Wu}^{\mathrm{a}, \mathrm{b}}$ *
}

${ }^{a}$ Shenzhen Key Laboratory of Affective and Social Cognitive Science, Shenzhen University, Shenzhen, China

${ }^{\mathrm{b}}$ School of Psychology, Shenzhen University, Shenzhen, China

${ }^{\mathrm{c}}$ Division of Psychology, School of Applied Sciences, Abertay University, Dundee, United Kingdom

${ }^{\mathrm{d}}$ School of Business Administration, Zhejiang University of Finance and Economics, Hangzhou, China

${ }^{\mathrm{e}}$ School of Psychology, Shanghai University of Sport, Shanghai, China

${ }^{*}$ Correspondence: Yin Wu, School of Psychology, Shenzhen University, Shenzhen, China.

Tel: +86-755-26532350 E-mail: yinwu0407@gmail.com 


\begin{abstract}
Assessing dominance is important for effective social interactions, and prior research suggests that testosterone is associated with men's dominance perceptions. The present study tested for a causal effect of exogenous testosterone on men's sensitivity to vocal cues of other men's dominance, an important parameter in male-male competition across species. One hundred and thirty-nine Chinese men received a single dose $(150 \mathrm{mg})$ of testosterone or placebo gel in a double-blind, placebo-controlled, between-participant design. Participants reported their own dominance and judged other men's dominance from voices. Men's dominance sensitivity was significantly weaker in the testosterone group compared to those in the placebo group. Moreover, men's dominance sensitivity was negatively associated with their self-reported dominance in our Chinese sample, consistent with findings from Western populations. These results indicate that exogenous testosterone has a causal effect in decreasing men's dominance sensitivity, consistent with the Challenge Hypothesis, suggesting that the fluctuation of testosterone concentration mediates individuals' behaviors. Additionally, the present study could motivate further work on vocal assessment in the context of competition in humans and other species.
\end{abstract}

Keywords: testosterone; dominance; voice; sexual dimorphism; intrasexual competition 


\section{Introduction}

Sexual selection theories provide an explanatory framework for intrasexual competition (see Archer, 2009; Wilson et al., 2014; Wrangham, 2018 for discussion), as death from intrasexual competition represented an important selection pressure in ancestral societies (Bowles, 2009; Keeley, 1996; Manson et al., 1991; Walker, 2001) and may have been fundamental to the evolution of group-based cooperation (Choi \& Bowles, 2007) and social intelligence (Flinn et al., 2005). One aspect of social intelligence is the ability to assess traits related to dominance in social partners, to reduce the costs of conflict such as lost resources, injury, or death (Puts, 2010; Sell et al., 2009a). Indeed, even in light of a historical decline in harm incurred from physical conflicts (i.e., on aggregate, Pinker, 2011), dominance assessment is still functional as the costs of underperceiving these traits are more substantial than the costs of overperceiving them (i.e., Error Management Theory; Haselton, \& Buss, 2000; Johnson et al., 2013). Accordingly, dominance is one of the two primary dimensions in social perceptions of both faces (Oosterhof \& Todorov, 2008; see also Sutherland et al., 2013) and voices (McAleer et al., 2014). In sum, attending to cues of dominance is critical for effective social interactions.

Traits exaggerated to a greater extent in one sex than the other are attended to in dominance assessment and within-sex competition across many species (Reby et al., 2005; Pitcher et al., 2015; see Emlen, 2008 and Santos et al., 2011 for reviews), and maybe exaggerated as dominance rank increases (Setchell \& Dixson, 2001). In humans, masculine physical characteristics are associated with dominance when individuals judge men across different modalities (e.g., DeBruine et al., 2006; Frederick \& Haselton, 2007; Jones et al., 2010; Neave \& Shields, 2008; Perrett et al., 1998) such as vocal masculinity (e.g., Puts et al., 2012; see Watkins \& Pisanski, 2016 for review). Conspecifics vary in their dominance, however, and classic models within evolutionary biology acknowledge that this is important in the escalation of conflict (Maynard Smith \& Price, 1973). Accordingly, sensitivity to physical cues of dominance may vary in light of the perceiver's own dominance, as less-dominant individuals incur greater costs from underperceiving these cues (Watkins et al., 2010a, 2010b). Consistent with this proposal, psychometric and physical proxies for dominance (i.e., height, 
reviewed in Stulp et al., 2015) may impact men's perception to other men's dominance (Watkins et al., 2010a). Thus, sexually dimorphic physical characteristics are correlated with dominance, while social perceptions of this trait vary systematically between observers.

Testosterone is associated with men's social perceptions and behaviors, such as mate preferences (Han et al., 2020; Welling et al., 2008), social judgments of trustworthiness (Bird et al., 2017), cognitive reflection (Nave et al., 2018), and aggressive behavior (Carré et al., 2017). The Challenge Hypothesis provides a theoretical framework to explain the relationship between testosterone and behavior, which was initially developed to explain seasonal fluctuations of testosterone levels in birds (Wingfield et al., 1990). It assumes that testosterone levels are not static but fluctuate in response to cues of challenge in the environment (e.g., parenting, breeding, and competition for mates), and these challenge-induced fluctuations in testosterone levels may, in turn, modulate one's behavior (Muller, 2017; Wingfield et al., 1990; see Geniole et al., 2020 for a recent review). Similarly in humans, increases in testosterone levels may interact with individual's behaviors and/or mental processes that increase fitness in response to challenge (Archer, 2006), such as mating (Goldey \& van Anders, 2011, 2012; Roney et al., 2007; van der Meij et al., 2008), and competition (Carré et al., 2009; Mehta \& Josephs, 2010).

In the current study, we aim to test whether pharmacologically induced testosterone increase influenced men's assessment of other men's dominance. The assessment of other men's dominance is an important cognitive function within same-sex competition, which may influence the likelihood of conflict escalation (versus withdrawal). Direct evidence for a causal effect of testosterone on men's dominance perception is rare (see Kandrik et al., 2016 for a study of natural variation in male testosterone levels and their voice perception). However, previous research has shown that after men were primed with victory, which is associated with testosterone increases (Geniole et al., 2017), men are less sensitive to facial cues of other men's dominance (Watkins \& Jones, 2012), defined as a low strength of association between masculine physical characteristics and perceived dominance (Watkins et al., 2010b). In addition, dominant male traits are positively associated with basal testosterone 
levels (Carré et al., 2009; Sellers et al., 2007; Turan et al., 2014), and a rise in testosterone improves men's self-assessments of their dominance (Welling et al., 2016). Thus, we predicted that testosterone administration would decrease men's sensitivity to vocal cues of dominance in other men (Hypothesis 1).

Previous research measured dominance sensitivity as the extent to which men perceive masculinized versions of stimuli to be more dominant than feminized versions (Watkins et al., 2010a, 2010b; Watkins \& Jones, 2012) by systematically manipulating pitch in voices (Watkins et al., 2010a). Here, we measured two sexually dimorphic acoustic properties of voices: $f_{\mathrm{o}}$ (perceived as pitch) and formant position ( $P f$, aggregated formant frequencies, see Puts et al., 2012). Low values on both parameters are an index of vocal masculinity, as both values are typically smaller in men than in women, and are negatively related to perceptions of men's dominance (Puts et al., 2012). Our measurements improve upon the vocal parameters in Watkins et al. (2010a), as formant frequency is a stronger predictor of body size than pitch (see Pisanski et al., 2014 for a meta-analytic review), with size as an index of traits related to dominance (reviewed in Stulp et al., 2015). We investigated responses to these vocal parameters in a new paradigm involving natural (unmanipulated) variation in male speech. Here, dominance sensitivity is defined as the extent to which the objective differences in $P f$ or $f_{\mathrm{o}}$ have an effect on dominance perception. For men who are particularly sensitive to vocal cues of male dominance, the same objective differences in $P f$ or $f_{\mathrm{o}}$ would have a stronger effect on their dominance perceptions, compared to men who are less sensitive to vocal cues of male dominance.

As prior evidence for individual differences in dominance sensitivity is predominantly based on Western samples (Watkins et al., 2010a, 2010b), the present study also sought to replicate this pattern of results in a non-Western (Chinese) sample. Thus, in addition to testing for the effects of exogenous testosterone on men's dominance perception, we also examined whether men's own dominance influenced their dominance sensitivity in a Chinese sample. Based on previous research (Watkins et al., 2010b), we hypothesized that men's own dominance could be negatively correlated with their dominance sensitivity in a Chinese sample (Hypothesis 2). 


\section{Methods}

\subsection{Participants}

One hundred and forty healthy Chinese men participated in this experiment. Individuals who took psychotropic medications or had any neurological/psychiatric disorders were not eligible to participate. Participants were asked to abstain from alcohol, caffeine, and smoking for 24 hours prior to the experimental session. This experiment was approved by the Shenzhen University Medical Research Ethics Committee and complied with the Declaration of Helsinki. Participants were reimbursed 45 Chinese yuan ( 7 US dollars) per hour. All participants provided written informed consent. One participant (in the placebo condition) was excluded from analysis, as he provided the same response across trials. The final sample size for analysis was 139 males ( $M_{\text {age }}=20.76$ years, $S D=1.87$, age range $=18$-26 years).

\subsection{Stimuli}

The stimuli consisted of 43 Chinese young adult male voice samples, which were recorded using an Audio-Technica AT-4041 cardioid condenser microphone at a sampling rate of 44.1 kHz at 16-bit amplitude quantization. The word “Hi” (in Chinese “海”) was extracted from each recording for use in the experiment. The sound pressure level of all voices was normalized to 70dB SPL using the root mean squared method. All acoustic measurements were made using Praat (Boersma \& Weenink, 2013). Specifically, $f_{\mathrm{o}}(M=129.28 \mathrm{~Hz}, S D=$ 18.05) was measured via Praat's autocorrelation algorithm with a search range of $65-300 \mathrm{~Hz}$ (Pisanski et al., 2014). We measured $F_{1}$ to $F_{4}$ using Praat's Burg Linear Predictive Coding (LPC) algorithm, with the maximum formant set to $5000 \mathrm{~Hz}$. Formants were first overlaid on a spectrogram and formant number was manually adjusted until the best visual match of predicted and observed formants were obtained. These techniques and settings are recommended by the Praat manual (Boersma \& Weenink, 2013; see also Pisanski et al., 2014). $\operatorname{Pf}(M=0, S D=0.70)$ were calculated following Puts et al. (2012).

\subsection{Procedure}


All participants arrived at the laboratory between 11:00 and 14:00. After providing informed consent, they completed a short questionnaire, consisting of demographic information and a self-reported dominance measure ("How dominant do you consider yourself to be?" on a 1 "very submissive" to 7 "very dominant" scale). Then, participants were randomly assigned to one of two experimental conditions (Treatment): a single dose of testosterone [Androgel ${ }^{\circledR}$ ] or placebo gel. We used a double-blind, placebo-controlled, between-subjects design (i.e., each participant only came to the laboratory once). Participants in the testosterone condition ( $\mathrm{N}=$ 70) received a single dose of testosterone gel, containing $150 \mathrm{mg}$ testosterone [Androgel ${ }^{\circledR}$ ], while those in the placebo condition $(\mathrm{N}=70, N=69$ for the final analysis as one participant provided the same response across trials) received a colorless hydroalcoholic gel. The dosing and pharmacokinetics of a single dose of Androgel is well established for men and used in previous studies (Bird et al., 2016; Eisenegger et al., 2013; Welling et al., 2016; Wu et al., 2018). In both conditions, a trained male research assistant, who was blind to both the study purpose and the experimental condition, applied the gel to the upper arms and shoulders of participants. During the waiting period, participants rested in the testing cubicles and were provided with books and newspapers.

\subsection{Vocal dominance judgment task}

The vocal dominance judgment task commenced three hours after gel administration. This time point was chosen based on previous pharmacokinetic data, where men's testosterone levels peak three hours after Androgel administration (Eisenegger et al., 2013; Wu et al., 2018). The vocal dominance judgment task was administered on laptops (ThinkPad T460) in the laboratory, with each participant sitting in a quiet single room. All voices were set at a constant volume and played via headphones (Sennheiser HD 280 Pro). Participants rated each voice on dominance from 1 (low) to 9 (high), with trial order fully randomized. All 43 voice samples were rated within one block and each voice sample was played only once.

\subsection{Statistical analysis}

We conducted a linear mixed effect model to analyze the effect of testosterone on the relationship between vocal dominance judgments and sexually dimorphic vocal 
characteristics. Analyses were conducted using R version 3.6.0 (R Core Team, 2019), with lmerTest version 3.10 (Kuznetsova et al., 2017). Before analysis, the treatment variable was coded as: placebo $(-0.5)$ vs. testosterone $(+0.5) \cdot f_{\mathrm{o}}$ and own dominance scores were standardized, however, $P f$ was not standardized as it was calculated via averaged z-scores of $F_{1}$ to $F_{4}$. In the model, the dependent variable was vocal dominance ratings from 1 (low) to 9 (high), and the fixed-effect factors were: treatment, own dominance scores, $f_{\mathrm{o}}, P f$, and all possible combinations of their interactions. Subject ID and voice ID were entered into the model as random-effect factors, following Barr et al. (2013) and Barr (2013). Additionally, we tested whether the two treatment groups differed in their own dominance scores, as previous research suggested that men's own dominance is correlated with their dominance sensitivity (Watkins et al., 2010b).

\section{Results}

The results of the linear mixed effect model are presented in Table 1. Both $P f(\beta=-0.53, S E=$ $0.11, t(42.79)=-4.97, p<.001)$ and $f_{\mathrm{o}}(\beta=-0.51, S E=0.07, t(42.79)=-6.83, p<.001)$ were negatively associated with the ratings of vocal dominance, suggesting that masculine male voices (i.e., lower $f_{\mathrm{o}}$ and $P f$ ) were perceived as more dominant than feminine male voices. Moreover, there was a main effect of participants' own dominance $(\beta=-0.27, S E=0.06$, $t(14.13)=-4.22, p<.001)$, indicating that men who perceived themselves as less dominant rated other men's vocal dominance higher. The main effect of treatment was not significant $(\beta$ $=0.06, S E=0.13, t(14.13)=0.46, p=.645)$.

Table 1. Model of Dominance Rating Using Linear Mixed Effect Model with Random Effects.

\begin{tabular}{ccccccc}
\hline & $\beta$ & $95 \% \mathrm{CI}$ & $\mathrm{SE}$ & $t$ & $p$ \\
\hline Intercept & 4.85 & $4.66,5.03$ & 0.09 & 51.23 & $<.001$ & $* * *$ \\
$P f$ & -0.53 & $-0.74,-0.32$ & 0.11 & -4.97 & $<.001$ & $* * *$ \\
$f_{\mathrm{o}}$ & -0.51 & $-0.65,-0.36$ & 0.07 & -6.83 & $<.001$ & $* * *$ \\
Treatment & 0.06 & $-0.19,0.31$ & 0.13 & 0.46 & 0.645 \\
\hline
\end{tabular}




\begin{tabular}{|c|c|c|c|c|c|c|}
\hline Own dominance & -0.27 & $-0.40,-0.15$ & 0.06 & -4.22 & $<.001$ & $* * *$ \\
\hline$P f \times f_{\mathrm{o}}$ & 0.01 & $-0.20,0.21$ & 0.11 & 0.07 & 0.946 & \\
\hline$P f \mathrm{x}$ Treatment & 0.11 & $0.01,0.21$ & 0.05 & 2.19 & 0.029 & $*$ \\
\hline Pf $\mathrm{x}$ Own dominance & 0.06 & $0.01,0.11$ & 0.03 & 2.26 & 0.024 & * \\
\hline$f_{\mathrm{o}} \mathrm{x}$ Treatment & 0.03 & $-0.04,0.10$ & 0.04 & 0.97 & 0.335 & \\
\hline$f_{\mathrm{o}} \mathrm{x}$ Own dominance & -0.04 & $-0.07,0.00$ & 0.02 & -1.95 & 0.051 & \\
\hline Treatment $\mathrm{x}$ Own dominance & 0.05 & $-0.21,0.31$ & 0.13 & 0.38 & 0.706 & \\
\hline $\operatorname{Pf} \mathrm{x} f_{\mathrm{o}} \mathrm{x}$ Treatment & -0.04 & $-0.14,0.06$ & 0.05 & -0.83 & 0.408 & \\
\hline Pf $\mathrm{x} f_{\mathrm{o}} \mathrm{x}$ Own dominance & 0.03 & $-0.02,0.08$ & 0.03 & 1.20 & 0.231 & \\
\hline Pf $\mathrm{x}$ Treatment $\mathrm{x}$ Own dominance & 0.04 & $-0.07,0.16$ & 0.06 & 0.73 & 0.471 & \\
\hline$f_{\mathrm{o}} \mathrm{x}$ Treatment $\mathrm{x}$ Own dominance & 0.05 & $-0.03,0.13$ & 0.04 & 1.34 & 0.188 & \\
\hline$P f \times f_{\mathrm{o}} \mathrm{x}$ Treatment $\mathrm{x}$ Own dominance & -0.09 & $-0.21,0.02$ & 0.06 & -1.61 & 0.114 & \\
\hline
\end{tabular}

139 subjects, 5977 observerations. Log Likelihood: -10078.8

There was a significant interaction between $P f$ and treatment $(\beta=0.11, S E=0.05, t(575.40)=$ $2.19, p=.029)$, suggesting that our experimental manipulation had a direct effect on the salience of this vocal parameter when judging men's dominance (see Figure 1). This interaction was interpreted by examining the association between $P f$ and dominance ratings in each treatment group. Although dominance ratings were negatively associated with $P f$ in both groups, this association was weaker in the testosterone group $(\beta=-0.48, S E=0.11, t(42.56)=$ $-4.46, p<.001)$ than it was in the placebo group $(\beta=-0.59, S E=0.11, t(42.72)=-5.15, p$ $<.001)$. In other words, men who are given testosterone perceived the same objective differences in $P f$ as less salient when evaluating men's dominance, compared to men in the placebo group, indicating that testosterone decreases men's sensitivity to cues of dominance in male voices.

Notably, there was no significant difference between the two groups in self-rated dominance $\left(M_{\text {Testosterone }}=4.20, S D_{\text {Testosterone }}=1.22, M_{\text {Placebo }}=4.22, S D_{\text {Placebo }}=1.10, t(135.79)=0.096, p\right.$ 
$=.930$ ) before gel administration. Thus, differences in dominance sensitivity between the two treatment groups were not an artifact of differences in those groups' self-rated dominance.

There was a significant interaction between $P f$ and men's own dominance, on dominance ratings $(\beta=0.06, S E=0.03, t(575.40)=2.26, p=.024)$, indicating that men's own dominance was related to the association between $P f$ and vocal dominance perception. Specifically, the negative association between $P f$ and dominance ratings was weaker in dominant men (high own dominance $=1 S D$ above mean; $\beta=-0.56, S E=0.14, t(42.56)=-4.06, p<.001)$ than it was in less-dominant men (low own dominance $=1 S D$ below mean; $\beta=-0.64, S E=0.11$, $t(42.61)=-5.69, p<.001$, see Figure 2). This result indicated that men's dominant sensitivity was negatively associated with their own dominance.

-----------Insert Fig. 2 about here-----------

\section{Discussion}

The present study investigated the effect of exogenous testosterone on men's sensitivity to vocal cues of dominance in other men. The results showed that men's dominance sensitivity was significantly reduced in those given testosterone compared to men given placebo, providing direct evidence that exogenous testosterone has a causal effect on men's dominance perception. Moreover, the experiment also revealed that men's dominance sensitivity was negatively associated with their own dominance in our Chinese sample, providing converging evidence with research on Western populations (Watkins et al., 2010a).

The effect of exogenous testosterone on men's dominance sensitivity may be due to increases in self-perceived dominance that are induced by testosterone administration, which, in turn, decreases their dominance sensitivity. Specifically, Welling et al. (2016) demonstrated that exogenous testosterone increased men's perceptions of their own dominance. Furthermore, it has been shown that men's perception of their own dominance was negatively associated with their dominance sensitivity (Watkins et al., 2010b), which was also found in our Chinese sample. According to Error management theory (Haselton \& Buss, 2000), the costs of 
underperceiving (versus overperceiving) traits related to dominance are greater for less-dominant individuals (i.e., Watkins et al., 2010a, 2010b; see Johnson et al., 2013 for a theoretical overview). Our data suggest that less-dominant men, in the absence of experimentally-induced testosterone, are more sensitive to vocal cues of other men's dominance.

As testosterone increases during competition may cause an increase in aggressive behavior (Carré et al., 2013), the decreased dominance sensitivity observed after testosterone administration may represent a social-cognitive mechanism involved in the escalation of confrontation or aggression. In same-sex contests, it would be functional to avoid escalation of conflict with masculine rivals, as masculine physical characteristics are positively associated with physical dominance (e.g., body size, strength; Windhager et al., 2011). However, men who are less sensitive to cues of dominance in rivals (i.e., testosterone administration group) may, in turn, be more likely to engage in costly confrontations by underperceiving traits related to a rival's formidability. Pending further work, these findings may have practical applications in understanding the hormonal correlates, and contexts that motivate risky aggression. Our male sample did not differ in their self-reported dominance before our manipulation, which had a direct effect on judgments that may underpin indiscriminate confrontation. In sum, the effects of testosterone on men's dominance perception may be an important underlying mechanism that increases men's aggressive behavior.

Other work provides converging evidence that testosterone undermines dominance-related decision-making. Geniole et al. (2019) found that a rise in testosterone blunted "threat premium" among men in the context of a competitively framed ultimatum game. The threat premium is an effect where more dominant individuals are ceded more resources. Our work complements Geniole et al. (2019)'s findings, as they both suggest that fluctuations in testosterone levels recalibrate assessments related to dominance, modulating appearance-based inferences about the target based on facial (Geniole et al., 2019) and/or vocal (the current study) cues. Both findings are consistent with the Challenge Hypothesis, 
where testosterone acts as a hormonal mechanism for facilitating competition in challenging contexts (Muller, 2017; Wingfield et al., 1990). Increases in self-assessed dominance (Welling et al., 2016) and reductions in the threat premium afforded to dominant individuals may, in turn, increase the likelihood of competition for resources.

Men's testosterone levels fluctuate in different contexts, and testosterone motivates mate preference/pursuit (e.g., Welling et al., 2008; Han et al., 2020), and competition for mates (see, e.g., Archer, 2006 for review), while decreasing in contexts where investment in resulting offspring may be of greater concern (e.g., Gettler et al., 2011). Although the current study did not directly manipulate these contexts or environments, exogenous administration of testosterone mimics contexts in which the motive to compete may be relatively intense (i.e., in light of the Challenge Hypothesis, see, e.g., Archer, 2006 for review), and when the costs of conflict are reduced (i.e., in light of competitive victory, Geniole et al., 2017), and 'winner-loser' effects (reviewed in Hsu \& Wolf, 2001; Hsu et al., 2006) motivate future behaviors. As testosterone is responsive to context and may fine-tune male psychology for effective competition (e.g., Carré, \& Archer, 2018; for a review see Geniole \& Carré, 2018), our findings extend this research, with the first direct evidence showing that testosterone influences a fundamental dimension of social perception in men (i.e., dominance perception; McAleer et al., 2014; Oosterhof \& Todorov, 2008).

Notably, we observed no general treatment effect. Our findings were specific to testosterone's effect on the perception of men's dominance derived from formant frequencies, but not pitch, the former of which is a stronger component in perceptions of traits related to male dominance such as size (Pisanski et al., 2014). Our findings complement work in other species, where this parameter is important in assessments of fighting ability from vocalizations (see Raine et al., 2019 for a recent review). Moreover, the current findings extend research on the role of competition-related factors (e.g., the perceiver's own dominance) on social perceptions of others (e.g., Watkins et al., 2010b), by demonstrating that they are observed in non-Western samples. This is consistent with Scott et al. (2014), 
showing a positive association between facial masculinity and perceived aggressiveness (a proxy for dominance; Lefevre \& Lewis, 2014) across different cultures.

It may be surprising that there is no treatment effect on pitch-related dominance perception, as pitch is negatively associated with perceived dominance and traits related to formidability (e.g., Cheng et al., 2016; Puts \& Aung, 2019; Puts, Gaulin, \& Verdolini, 2006). However, in information-rich contexts, $f_{\mathrm{o}}$ only explains around $3-4 \%$ of the variance in perceived dominance (cf. meta-analysis in Aung \& Puts, 2020), and pitch is a poor indicator of physical dominance (Armstrong et al., 2019; Feinberg et al., 2018, 2019). Meta-analyses indicate that pitch explains less than $2 \%$ of the variance in men's body size, whereas formant frequencies explain up to $10 \%$ of the variance in men's body size (Pisanski et al., 2014). In sum, formants are better than pitch in indexing physical size (i.e., a cue to dominance), even if the pitch may still be a reliable signal of aggressive intent (see Zhang \& Reid, 2017 for discussion). Thus, the null result of our treatment effect on dominance perception derived from pitch may be attributable to factors (a) our experiment context is neutral (i.e., a non-competitive scenario), where gauging intent to inflict harm may be less of a concern, and (b) pitch is a weak predictor of actual physical dominance (e.g., body size, Pisanski et al., 2014; strength, Han et al., 2018).

\section{Limitations and future directions}

While previous work investigated dominance sensitivity based on manipulated voices (Watkins et al., 2010a), our work suggests that differences in dominance sensitivity are also observed when examining responses to men's natural voices, which is arguably a more valid context for making inferences on social responses to voices outside of the laboratory.

Moreover, while we observed systematic variation in the perception of dominance in response to relatively benign vocal utterances (i.e., someone saying "Hi"), the effects could be substantial in the real world, if the information conveyed by speakers is relatively threatening. As our study did not manipulate contexts/environments experimentally, future research could explore the effect of exogenous testosterone on men's dominance perception in a variety of social contexts, such as competitive and collaborative situations. 
Another limitation of the current study is that we measured participants' self-reported dominance via a single item measure. Although brief self-rated measures tend to correlate highly with objective measures of male dominance (e.g., Sell et al., 2009b), our current measure may not capture all components or traits related to dominance, such as leadership, prestige, competitiveness, and aggressiveness. Future research could develop this work by examining multiple traits related to dominance, including objective measures, and self- and peer-ratings.

Additionally, while our experiment was conducted three hours after Androgel administration, another experiment with the same dosage is conducted one-hour post administration of Androgel (Carré, et al., 2017). While we followed Eisengger et al. (2013) and Wu et al. (2018), who show that testosterone levels peak three hours after testosterone administration, the data in Carré et al. (2017) suggests that testosterone concentrations are elevated within 60 minutes and sustained for three hours post-dose. Indeed, testosterone levels at both one- and three hours post-dose are significantly higher than pre-dose levels across these experiments, although $\mathrm{Wu}$ et al. (2018) show that testosterone levels are higher at three hours post-dose compared to one-hour post-dose. Therefore, the condition of testosterone levels meets the purpose of the corresponding studies (Carré, et al., 2017; Wu et al., 2018) as well as the current study. We encourage future research to continue investigating the time course of Androgel administration and its corresponding effects on behavior.

\section{Conclusion}

To conclude, we provided a direct test of the hormonal basis of dominance perception derived from vocal cues. The present study demonstrated that exogenous testosterone decreases men's sensitivity to vocal cues of other men's dominance, consistent with the Challenge Hypothesis, suggesting that the fluctuation of testosterone concentration mediates individuals' behaviors. Moreover, we also corroborate the finding that individual differences in the costs of engaging in conflict shape dominance sensitivity. In our Chinese sample, less-dominant men are more sensitive to vocal cues of male dominance, consistent with past findings from the Western samples. Collectively, our findings suggest that intrasexual selection has shaped voice 
perception in humans, which may have implications for future work on fighting assessment from vocal cues in humans and across species.

\section{Conflict of interest statement}

None of the authors have conflicts of interests to declare.

\section{Acknowledgement}

This work was supported by the National Natural Science Foundation of China (31872784, 31600923, 31600928), Guangdong Educational Science Research Fund (2018GXJK150), Shenzhen University Research Fund (SZUGS2020JG07, 860/000002110601) and the Shenzhen Peacock Plan (827-000233) to YW. The funding sources had no further role in the study design, data collection, analysis, interpretation, and decision to submit this manuscript for publication. 


\section{References}

Archer, J. (2009). Does sexual selection explain human sex differences in aggression? Behavioral and Brain Sciences, 32, 1-63.

Archer, J. (2006). Testosterone and human aggression: An evaluation of the challenge hypothesis. Neuroscience and Biobehavioral Reviews, 30, 319-345.

Armstrong, M. M., Lee, A. J., \& Feinberg, D. R. (2019). A house of cards: bias in perception of body size mediates the relationship between voice pitch and perceptions of dominance. Animal Behaviour, 147, 43-51.

Aung, T., \& Puts, D. (2020). Voice pitch: a window into the communication of social power. Current opinion in psychology, 33, 154-161.

Barr, D. J. (2013). Random effects structure for testing interactions in linear mixed-effects models. Frontiers in psychology, 4, 328.

Barr, D. J., Levy, R., Scheepers, C., \& Tily, H. J. (2013). Random effects structure for confirmatory hypothesis testing: Keep it maximal. Journal of memory and language, 68(3), 255-278.

Bird, B. M., Geniole, S. N., Little, A. C., Moreau, B. J., Ortiz, T. L., Goldfarb, B., ... \& Carré, J. M. (2017). Does exogenous testosterone modulate men's ratings of facial dominance or trustworthiness?. Adaptive Human Behavior and Physiology, 3(4), 365-385.

Bird BM, Welling, LL, Ortiz, TL, Moreau, BJ, Hansen, S, Emond, M, ... \& Carré, JM. (2016 ). Effects of exogenous testosterone and mating context on men's preferences for female facial femininity. Hormones and Behavior. 85, 76-85.

Boersma, P., \& Weenink, D. (2013). Praat: Doing phonetics by computer [Computer Program]. Retrieved from http://www.fon.hum.uva.nl/praat/.

Bowles, S. (2009). Did warfare among ancestral hunter-gatherers affect the evolution of human social behaviors? Science, 324, 1293-1298.

Carré, J. M., \& Archer, J. (2018). Testosterone and human behavior: The role of individual and contextual variables. Current opinion in psychology, 19, 149-153.

Carré, J. M., Campbell, J. A., Lozoya, E., Goetz, S. M., \& Welker, K. M. (2013). Changes in testosterone mediate the effect of winning on subsequent aggressive behaviour. Psychoneuroendocrinology, 38(10), 2034-2041. 
Carré, J. M., Geniole, S. N., Ortiz, T. L., Bird, B. M., Videto, A., \& Bonin, P. L. (2017).

Exogenous testosterone rapidly increases aggressive behavior in dominant and impulsive men. Biological psychiatry, 82(4), 249-256.

Carré, J. M., Putnam, S. K., \& McCormick, C. M. (2009). Testosterone responses to competition predict future aggressive behaviour at a cost to reward in men. Psychoneuroendocrinology, 34(4), 561-570.

Choi, J. K. \& Bowles, S. (2007). The coevolution of parochial altruism and war. Science, 318, $636-640$.

Cheng, J. T., Tracy, J. L., Ho, S., \& Henrich, J. (2016). Listen, follow me: Dynamic vocal signals of dominance predict emergent social rank in humans. Journal of Experimental Psychology: General, 145(5), 536-547.

DeBruine, L. M., Jones, B. C., Little, A. C., Boothroyd, L. G., Perrett, D. I., Penton-Voak, I. S., Cooper, P. A., Penke, L., Feinberg, D. R. \& Tiddeman, B. P. (2006). Correlated preferences for facial masculinity and ideal or actual partner's masculinity. Proceedings of the Royal Society of London B, 273, 1355-1360.

Eisenegger, C., von Eckardstein, A., Fehr, E., \& von Eckardstein, S. (2013).

Pharmacokinetics of testosterone and estradiol gel preparations in healthy young men. Psychoneuroendocrinology, 38(2), 171-178.

Emlen, D. J. (2008). The evolution of animal weapons. Annual Review of Ecology, Evolution, and Systematics, 39, 387-413.

Feinberg, D. R., Jones, B. C., \& Armstrong, M. M. (2018). Sensory exploitation, sexual dimorphism, and human voice pitch. Trends in ecology \& evolution, 33(12), 901-903.

Feinberg, D R, Jones, B. C., \& Armstrong, M. M. (2019). No evidence that men's voice pitch signals formidability. Trends in Ecology \& Evolution, 34(3), 190-192.

Flinn, M.V., Geary, D.C. \& Ward, C.V. (2005). Ecological dominance, social competition, and coalitionary arms races: Why humans evolved extraordinary intelligence. Evolution and Human Behavior, 26(1), 10-46.

Frederick, D. A. \& Haselton, M. G. (2007). Why is muscularity sexy? Tests of the fitness indicator hypothesis. Personality and Social Psychology Bulletin, 33, 1167-1183. 
Geniole, S. N., Bird, B. M., Ruddick, E. L., \& Carré, J. M. (2017). Effects of competition outcome on testosterone concentrations in humans: An updated meta-analysis. Hormones and behavior, 92, 37-50.

Geniole, S. N., \& Carré, J. M. (2018). Human social neuroendocrinology: Review of the rapid effects of testosterone. Hormones and behavior, 104, 192-205.

Geniole, S. N., Proietti, V., Bird, B. M., Ortiz, T. L., Bonin, P. L., Goldfarb, B., Watson, N. V., \& Carré, J. M. (2019). Testosterone reduces the threat premium in competitive resource division. Proceedings of the Royal Society B, 286(1903), 20190720.

Geniole, S. N., Bird, B. M., McVittie, J. S., Purcell, R. B., Archer, J., \& Carré, J. M. (2020). Is testosterone linked to human aggression? A meta-analytic examination of the relationship between baseline, dynamic, and manipulated testosterone on human aggression. Hormones and behavior, 104644.

Gettler, L. T., McDade, T. W., Feranil, A. B. \& Kuzawa, C. W. (2011). Longitudinal evidence that fatherhood decreases testosterone in human males. Proceedings of the National Academy of Sciences USA, 108, 16194-16199.

Goldey, K. L., \& van Anders, S. M. (2011). Sexy thoughts: Effects of sexual cognitions on testosterone, cortisol, and arousal in women. Hormones and Behavior, 59(5), 754-764.

Goldey, K. L., \& van Anders, S. M. (2012). Sexual thoughts: Links to testosterone and cortisol in men. Archives of Sexual Behavior, 41(6), 1461-1470.

Han, C., Wang, H., Fasolt, V., Hahn, A. C., Holzleitner, I. J., Lao, J., ... \& Jones, B. C. (2018). No clear evidence for correlations between handgrip strength and sexually dimorphic acoustic properties of voices. American Journal of Human Biology, 30(6), e23178.

Han, C., Zhang, Y., Lei, X., Li, X., Morrison, E. R., \& Wu, Y. (2020). Single dose testosterone administration increases men's facial femininity preference in a Chinese population. Psychoneuroendocrinology, 115, 104630.

Haselton, M. G., \& Buss, D. M. (2000). Error management theory: A new perspective on biases in cross-sex mind reading. Journal of personality and social psychology, 78(1), $81-91$. 
Hsu Y., Earley, R. L. \& Wolf, L. L. (2006). Modulation of aggressive behaviour by fighting experience: mechanisms and contest outcomes. Biological Reviews, 81, 33-74.

Hsu, Y. \& Wolf, L. L. (2001). The winner and loser effect: what fighting behaviours are influenced? Animal Behaviour, 61, 777-786.

Johnson, D. D. P., Blumstein, D. T., Fowler, J. H. \& Haselton, M. G. (2013). The evolution of error: Error management, cognitive constraints and adaptive decision-making biases. Trends in Ecology and Evolution. 28 (8), 474-481.

Jones, B. C., DeBruine, L. M., Main, J. C., Little, A. C., Welling, L. L. M., Feinberg, D. R. \& Tiddeman, B. P. (2010). Facial cues of dominance modulate the short-term gaze-cuing effect in human observers. Proceedings of the Royal Society of London B, $277,617-624$.

Kandrik, M., Hahn, A. C., Wincenciak, J., Fisher, C. I., Pisanski, K., Feinberg, D. R., ... \& Jo nes, B. C. (2016). Are men's perceptions of sexually dimorphic vocal characteristics $r$ elated to their testosterone levels?PloS one, 11(11), e0166855.

Keeley, L. H. (1996). War before Civilization. The Myth of the Peaceful Savage. New York-Oxford: Oxford University Press.

Kuznetsova, A., Brockhoff, P. B., \& Christensen, R. H. B. (2017). lmerTest package: tests in linear mixed effects models. Journal of Statistical Software, 82(13).

Lefevre, C. E., \& Lewis, G. J. (2014). Perceiving aggression from facial structure: Further evidence for a positive association with facial width-to-height ratio and masculinity, but not for moderation by self-reported dominance. European Journal of Personality, 28(6), $530-537$.

Manson, J. H., Wrangham, R. W., Boone, J. L., Chapais, B., Dunbar, R. I. M., Ember, C. R., ... \& Paterson, J. D. (1991). Intergroup aggression in chimpanzees and humans [and comments and replies]. Current anthropology, 32(4), 369-390.

Maynard Smith, J. \& Price, G. R. (1973). The logic of animal conflict. Nature, 246, 15-18.

McAleer, P., Todorov, A. \& Belin, P. (2014). How do you say 'hello'? Personality impressions from brief novel voices. PLoS One, 9, e90779. 
Mehta, P. H., \& Josephs, R. A. (2010). Testosterone and cortisol jointly regulate dominance:

Evidence for a dual-hormone hypothesis. Hormones and behavior, 58(5), 898-906.

Muller, M. N. (2017). Testosterone and reproductive effort in male primates. Hormones and Behavior, 91, 36-51.

Nave, G., Nadler, A., Zava, D., \& Camerer, C. (2017). Single-dose testosterone administration impairs cognitive reflection in men. Psychological science, 28(10), 1398-1407.

Neave, N. \& Shields, K. (2008). The effects of facial hair manipulation on female perceptions of attractiveness, masculinity, and dominance in male faces. Personality and Individual Differences, 45, 373-377.

Oosterhof, N. N., \& Todorov, A. (2008). The functional basis of face evaluation. Proceedings of the National Academy of Sciences, 105(32), 11087-11092.

Pinker, S. (2011). The Better Angels of our Nature. New York, NY: Viking.

Pisanski, K., Fraccaro, P. J., Tigue, C. C., O'Connor, J. J., Röder, S., Andrews, P. W., ... \& Feinberg, D. R. (2014). Vocal indicators of body size in men and women: a meta-analysis. Animal Behaviour, 95, 89-99.

Perrett, D. I., Lee, K. J., Penton-Voak, I. S., Rowland, D. R., Yoshikawa, S., Burt, D. M., Henzi, S. P., Castles, D. I. \& Akamatsu, S. (1998). Effects of sexual dimorphism on facial attractiveness. Nature, 394, 884-887.

Pitcher, B. J., Briefer, E. F. \& McElligott, A. G. (2015). Intrasexual selection drives sensitivity to pitch, formants and duration in the competitive calls of fallow bucks. BMC Evolutionary Biology, 15, 149.

Puts, D. A. (2010). Beauty and the beast: Mechanisms of sexual selection in humans. Evolution and Human Behavior, 31(3), 157-175.

Puts, D. A., Apicella, C. L., \& Cárdenas, R. A. (2012). Masculine voices signal men's threat potential in forager and industrial societies. Proceedings of the Royal Society B: Biological Sciences, 279(1728), 601-609.

Puts, D. A., \& Aung, T. (2019). Does men's voice pitch signal formidability? A reply to Feinberg et al. Trends in Ecology \& Evolution, 34(3), 189-190. 
Puts, D. A., Gaulin, S. J., \& Verdolini, K. (2006). Dominance and the evolution of sexual dimorphism in human voice pitch. Evolution and Human Behavior, 27(4), 283-296.

R Core Team (2019). R: A language and environment for statistical computing. R Foundation for Statistical Computing, Vienna, Austria.

Raine, J., Pisanski, K., Bond, R., Simner, J. \& Reby, D. (2019). Human roars communicate upper-body strength more effectively than do screams or aggressive and distressed speech. PLoS One, 14, e0213034.

Reby, D., McComb, K., Cargnelutti, B., Darwin, C., Fitch, W. T. \& Clutton-Brock, T. (2005). Red deer stags use formants as assessment cues during intrasexual agonistic interactions. Proceedings of the Royal Society of London B Biological Sciences, 272, 941-947.

Roney, J. R., Lukaszewski, A. W., \& Simmons, Z. L. (2007). Rapid endocrine responses of young men to social interactions with young women. Hormones and Behavior, 52(3), 326-333.

Santos, E. S. A., Scheck, D. \& Nakagawa, S. (2011). Dominance and plumage traits: meta-analysis and metaregression analysis. Animal Behaviour, 82, 3-19.

Sell, A., Cosmides, L., Tooby, J., Sznycer, D., von Rueden, C., \& Gurven, M. (2009a). Human adaptations for the visual assessment of strength and fighting ability from the body and face. Proceedings of the Royal Society B: Biological Sciences, 276(1656), $575-584$.

Sell, A., Tooby, J., \& Cosmides, L. (2009b). Formidability and the logic of human anger. Proceedings of the National Academy of Sciences, 106(35), 15073-15078.

Sellers, J. G., Mehl, M. R., \& Josephs, R. A. (2007). Hormones and personality: Testosterone as a marker of individual differences. Journal of Research in Personality, 41(1), 126-138.

Setchell, J. M. \& Dixson, A. F. (2001). Changes in the secondary sexual adornments of male mandrills (Mandrillus sphinx) are associated with gain and loss of alpha status. Hormones and Behavior, 39, 177-184.

Scott, I. M., Clark, A. P., Josephson, S. C., Boyette, A. H., Cuthill, I. C., Fried, R. L., ... \& Honey, P. L. (2014). Human preferences for sexually dimorphic faces may be 
evolutionarily novel. Proceedings of the National Academy of Sciences, 111(40), 14388-14393.

Stulp, G., Buunk, A. P., Verhulst, S. \& Pollet, T. V. (2015). Human height is positively related to interpersonal dominance in dyadic interactions. PLoS One, 10, e0117860.

Sutherland, C. A., Oldmeadow, J. A., Santos, I. M., Towler, J., Burt, M. D. \& Young, A. W. (2013). Social inferences from faces: Ambient images generate a three-dimensional model. Cognition, 127, 105-118.

Turan, B., Guo, J., Boggiano, M. M., \& Bedgood, D. (2014). Dominant, cold, avoidant, and lonely: Basal testosterone as a biological marker for an interpersonal style. Journal of Research in Personality, 50, 84-89.

van der Meij, L., Buunk, A. P., van de Sande, J. P., \& Salvador, A. (2008). The presence of a woman increases testosterone in aggressive dominant men. Hormones and Behavior, 54(5), 640-644.

Walker, P. L. (2001). A bioarcheological perspective on the history of violence. Annual Review of Anthropology, 30, 573-596.

Watkins, C. D., Fraccaro, P. J., Smith, F. G., Vukovic, J., Feinberg, D. R., DeBruine, L. M., \& Jones, B. C. (2010a). Taller men are less sensitive to cues of dominance in other men. Behavioral Ecology, 21(5), 943-947.

Watkins, C. D., Jones, B. C., \& DeBruine, L. M. (2010b). Individual differences in dominance perception: Dominant men are less sensitive to facial cues of male dominance. Personality and Individual Differences, 49(8), 967-971.

Watkins, C. D. \& Jones, B. C. (2016). Competition-related factors directly influence preferences for facial cues of dominance in allies. Behavioral Ecology and Sociobiology. 70 (12), 2071-2079.

Watkins, C. D., \& Jones, B. C. (2012). Priming men with different contest outcomes modulates their dominance perceptions. Behavioral Ecology, 23(3), 539-543.

Watkins, C. D. \& Pisanski, K. (2016). Vocal indicators of dominance. In Shackelford, T., Weekes-Shackelford, V. (Eds). Encyclopedia of Evolutionary Psychological Science. Springer, Cham. 
Welling, L. L., Jones, B. C., DeBruine, L. M., Smith, F. G., Feinberg, D. R., Little, A. C., \& Al-Dujaili, E. A. (2008). Men report stronger attraction to femininity in women's faces when their testosterone levels are high. Hormones and Behavior, 54(5), 703-708.

Welling, L. L., Moreau, B. J., Bird, B. M., Hansen, S., \& Carré, J. M. (2016). Exogenous testosterone increases men's perceptions of their own physical dominance. Psychoneuroendocrinology, 64, 136-142.

Wilson, M. L., Boesch, C., Fruth, B., Furuichi, T., Gilby, I. C., Hashimoto, C., et al. (2014). Lethal aggression in Pan is better explained by adaptive strategies than human impacts. Nature, 513, 414.

Windhager, S., Schaefer, K., \& Fink, B. (2011). Geometric morphometrics of male facial shape in relation to physical strength and perceived attractiveness, dominance, and masculinity. American Journal of Human Biology, 23(6), 805-814.

Wrangham, R. W. (2018). Two types of aggression in human evolution. Proceedings of the National Academy of Sciences USA, 115, 245-253.

Wingfield, J. C., Hegner, R. E., Dufty Jr, A. M., \& Ball, G. F. (1990). The" challenge hypothesis": theoretical implications for patterns of testosterone secretion, mating systems, and breeding strategies. The American Naturalist, 136(6), 829-846.

Wu, Y., Clark, L., Zilioli, S., Eisenegger, C., Gillan, C. M., Deng, H., \& Li, H. (2018). Single dose testosterone administration modulates emotional reactivity and counterfactual choice in healthy males. Psychoneuroendocrinology, 90, 127-133.

Zhang, J., \& Reid, S. A. (2017). Aggression in young men high in threat potential increases after hearing low-pitched male voices: two tests of the retaliation-cost model. Evolution and Human Behavior, 38(4), 513-521.

\section{Figure legend}

Figure 1. The effect of treatment on the relationship between $P f$ and vocal dominance judgments. The absolute value of the slope was lower in the testosterone group than the placebo group, indicating that the dominance rating in the testosterone group was less sensitive to $P f$ changes than it was in the placebo group. 
Figure 2. The effect of own dominance on the relationship between $P f$ and vocal dominance judgments. The absolute value of slope was lower in dominant men than it was in less dominant men, indicating that less dominant men were more sensitive to $P f$ changes than were dominant men, when judging men's dominance. Low own dominance $=1 \mathrm{SD}$ below the mean, $\beta($ slope $)=-0.64$; high own dominance $=1 \mathrm{SD}$ above the mean, $\beta($ slope $)=-0.56$. 


\section{Figures}

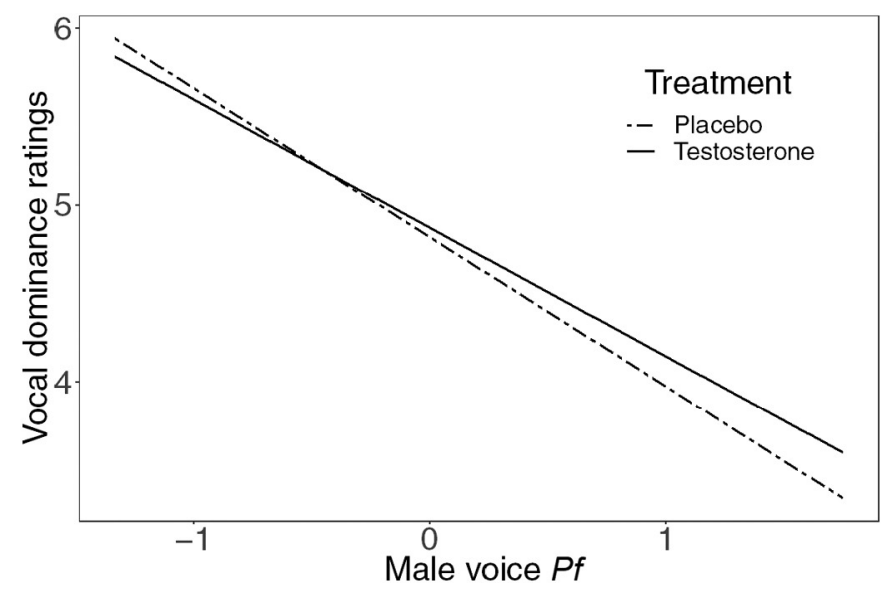

Figure 1.

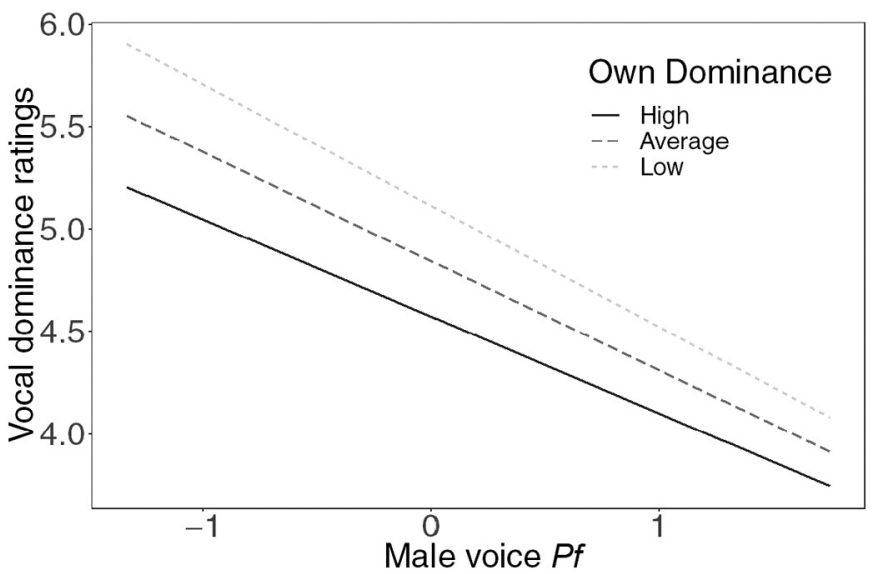

Figure 2. 